\title{
A Mobile Phone-Based Self-Monitoring Tool for Perioperative Gastric Cancer Patients With Incentive Spirometer: Randomized Controlled Trial
}

Ji Yeong Soh ${ }^{1 *}$, RN; Se Uk Lee ${ }^{2 *}$, MD; Inpyo Lee ${ }^{3}$, MS; Ki Sang Yoon ${ }^{4}$, BD; Changho Song ${ }^{3}$, BS; Nam Hun Kim ${ }^{5}$, MS; Tae Sung Sohn ${ }^{6}$, MD; Jae Moon Bae ${ }^{6}$, MD; Dong Kyung Chang ${ }^{1,7,8}$, MD; Won Chul Cha ${ }^{8,9,10}$, MD

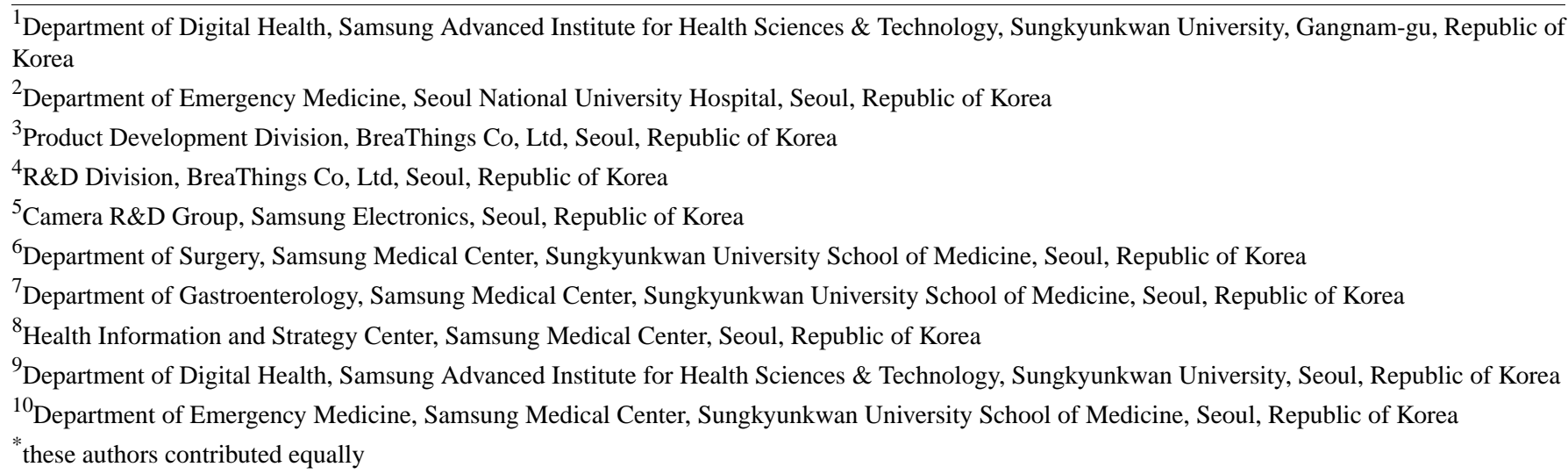

Corresponding Author:

Won Chul Cha, MD

Department of Digital Health

Samsung Advanced Institute for Health Sciences \& Technology

Sungkyunkwan University

81, Irwon-ro

Gangnam-gu

Seoul, 06351

Republic of Korea

Phone: 821053866597

Email: docchaster@gmail.com

\section{Abstract}

Background: An incentive spirometer (IS) is a medical device used to help patients improve the functioning of their lungs. It is provided to patients who have had any surgery that might jeopardize respiratory function. An incentive spirometer plays a key role in the prevention of postoperative complications, and the appropriate use of an IS is especially well known for the prevention of respiratory complications. However, IS utilization depends on the patient's engagement, and information and communication technology (ICT) can help in this area.

Objective: This study aimed to determine the effect of mobile ICT on the usage of an IS (Go-breath) app by postoperative patients after general anesthesia.

Methods: For this study, we recruited patients from April to May 2018, who used the Go-breath app at a single tertiary hospital in South Korea. The patients were randomly classified into either a test or control group. The main function of the Go-breath app was to allow for self-reporting and frequency monitoring of IS use, deep breathing, and active coughing in real time. The Go-breath app was identical for both the test and control groups, except for the presence of the alarm function. The test group heard an alarm every 60 min from 9 am to 9 pm for 2 days. For the test group alone, a dashboard was established in the nurse's station through which a nurse could rapidly assess the performance of multiple patients. To evaluate the number of performances per group, we constructed an incentive spirometer index (ISI).

Results: A total of 44 patients were recruited, and 42 of them completed the study protocol. ISI in the test group was 20.2 points higher than that in the control group (113.5 points in the test group and 93.2 points in the control group, $P=.22$ ). The system 
usability scale generally showed almost the same score in the 2 groups (79.3 points in the test group and 79.4 points in the control group, $P=.94)$. We observed that the performance rates of IS count, active coughing, and deep breathing were also higher in the test group but with no statistically significant difference between the groups. For the usefulness "yes or no" question, over $90 \%$ (38/42) of patients answered "yes" and wanted more functional options and information.

Conclusions: The use of the Go-breath app resulted in considerable differences between the test group and control group but with no statistically significant differences.

Trial Registration: ClinicalTrials.gov NCT03569332; https://clinicaltrials.gov/ct2/show/NCT03569332 (Archived by WebCite at http://www.webcitation.org/74ihKmQIX).

(JMIR Mhealth Uhealth 2019;7(2):e12204) doi: 10.2196/12204

\section{KEYWORDS}

incentive spirometer; mobile health; postoperative care; gastric cancer; motivation

\section{Introduction}

\section{Background}

Vigorous and multidisciplinary efforts are required to prevent postoperative complications following prolonged general anesthesia [1], and an incentive spirometer (IS) plays a key role, especially for patients with limited mobility [2]. An incentive spirometer is a medical device used to help patients improve the functioning of their lungs. It is provided to patients who have had any surgery that might jeopardize respiratory function. The IS is used for the prevention of atelectasis, hypoxemia, pneumonia, respiratory dysfunction, and pleural effusion [3,4]. However, IS utilization has remained the same since its initial development in the 1960s, and the usage protocol has not been standardized [5-8].

Although many mobile phone apps have been developed for self-management in various clinical settings, only a few cases showing their use in postoperative care were reported [9], even though subjective activity by patients can influence their clinical hospital outcomes. Therefore, with help from mobile information and communication technology (ICT), patients can be more engaged in behaviors that can lead to better clinical results $[3,10,11]$.

A mobile ICT for hospitalized postoperative patients can improve clinical outcomes by several pathways: it can encourage patients by informing them of important performance indices such as exercise duration [12-14], and it can connect the patient and provider with a real-time dashboard that can support prompt provider reactions. In a previous study, a postoperative group of patients using mobile ICT recovered significantly better than a control group [9].

\section{Objective}

Therefore, the goal of this study was to determine the effect of mobile ICT on the performance of postoperative patients using an IS (Go-breath) app after general anesthesia.

\section{Methods}

\section{Study Design}

This was a single-center, randomized controlled trial (RCT) assessing the effectiveness of an IS self-reporting app (Go-breath) to improve IS performance and effectiveness. This trial was registered with the US National Institutes of Health Clinical Trials Registry (NCT03569332).

\section{Study Setting}

This study was conducted at an academic tertiary center located in Seoul, Korea. The hospital's expertise is cancer care. It hosts approximately 2000 inpatient beds and registers approximately 8500 outpatients per day.

Gastric cancer is one of the major diseases treated in the institution. The hospital's Critical Pathway defines the routine care process for gastric cancer surgery as follows: The patient is admitted the evening before the surgery and discharged approximately 9 to 10 days after surgery-the discharge period of laparotomy is postoperative day (POD) 8 and for laparoscopy is POD 7-without complications; the patient receives instructions on the routine use of an IS before the surgery, and its use is initiated the morning after the surgery (POD 1).

\section{Study Participants}

Participants were enrolled from April to May 2018. We recruited patients from the surgical ward immediately after the admission process. Our eligibility criteria stipulated that patients were older than 18 years and planned to undergo robotic or laparoscopic surgery or a laparotomy. The enrollment was performed the day before the surgery, and the intervention was initiated the day after the surgery (POD 1). Following recruitment, participants were provided written informed consent and randomized using a Web-based random number generator and sealed enveloped in a 1:1 ratio. If the patient was in the intensive care unit (ICU) or in an emergency condition requiring nonelective surgery, he or she was excluded from the study. The patients were dropped from the study if the postoperative state of the patients was not difficult to predict in advance and if their postsurgical condition (and before the initiation of intervention) was consistent with the exclusion criteria such as ICU admission. Dropout was only permitted on the day of surgery (POD 0).

\section{Study Protocol}

Patients were allocated to the test and control groups after giving their consent for the study. Patients received a tablet with the Go-breath app installed, and they received information about the app and use of the IS for approximately $30 \mathrm{~min}$. The IS awareness session was carried out using either video clips 
(Multimedia Appendix 1) or nurses as part of the routine clinical process.

Generally, the nurses were encouraged to check the performance of the IS on the patients over 10 times every hour after the surgery, and some ward nurses checked the IS performance rate more than 10 times per hour from 9 am to $9 \mathrm{pm}$.

The Go-breath app was identical for both the test and control groups except for the alarm function. The test group heard an alarm every 60 min from 9 am to 9 pm during POD1-POD2 (a total of 24 hours). For the test group only, a dashboard was established in the nurse's station through which a nurse could rapidly assess the performance of multiple patients. On the other hand, the control group was not provided an alarm function or nurse dashboard identification. The control group only entered the number of IS performances using the app.

The measurement of IS use was unlimited, but the record of the Go-breath app and dashboard would show up to a maximum of 10 times per hour. We named this the incentive spirometer index (ISI), and a description of this index is provided in the major outcomes section. Termination of the study occurred in the morning of POD 3. Study assistants visited each patient, collected devices, conducted a short survey about usability among the patients and interviewed the patients for subjective opinions. Even though the study intervention lasted for only 2 days, the patients' outcomes were tracked until the day of discharge. An overview of the study protocol is provided in Figure 1.

\section{Device and System}

\section{Hardware and System Architecture}

The system was constructed based on the opinions of health providers and comprised a mobile phone app for patients and a server for medical staff. Patients could self-input their performance of IS, active coughing, and deep breathing every time. This information was transmitted to a nurse dashboard for a real-time check. All patients were given the same hardware (Galaxy tablet A 8.0, Samsung, purchased 2018) running Android 8.0, and the mobile Go-breath app was tested on Android 8.0 utilizing an Amazon Web service server (Figure 2).

Figure 1. Study protocol. Superscripted "a" indicates alarm every $50 \mathrm{~min}$ for insufficient during 9am-9pm (alarm off during 9pm-9am); "b" indicates calculation of performance score applies only to incentive spirometer (full score 240, 10 out of 10 points). V/S: blood pressure, fever, body temperature, respiration rate; CRP: C-reactive protein; IS: incentive spirometer; PA: posterior to anterior; WBC: white blood cell.

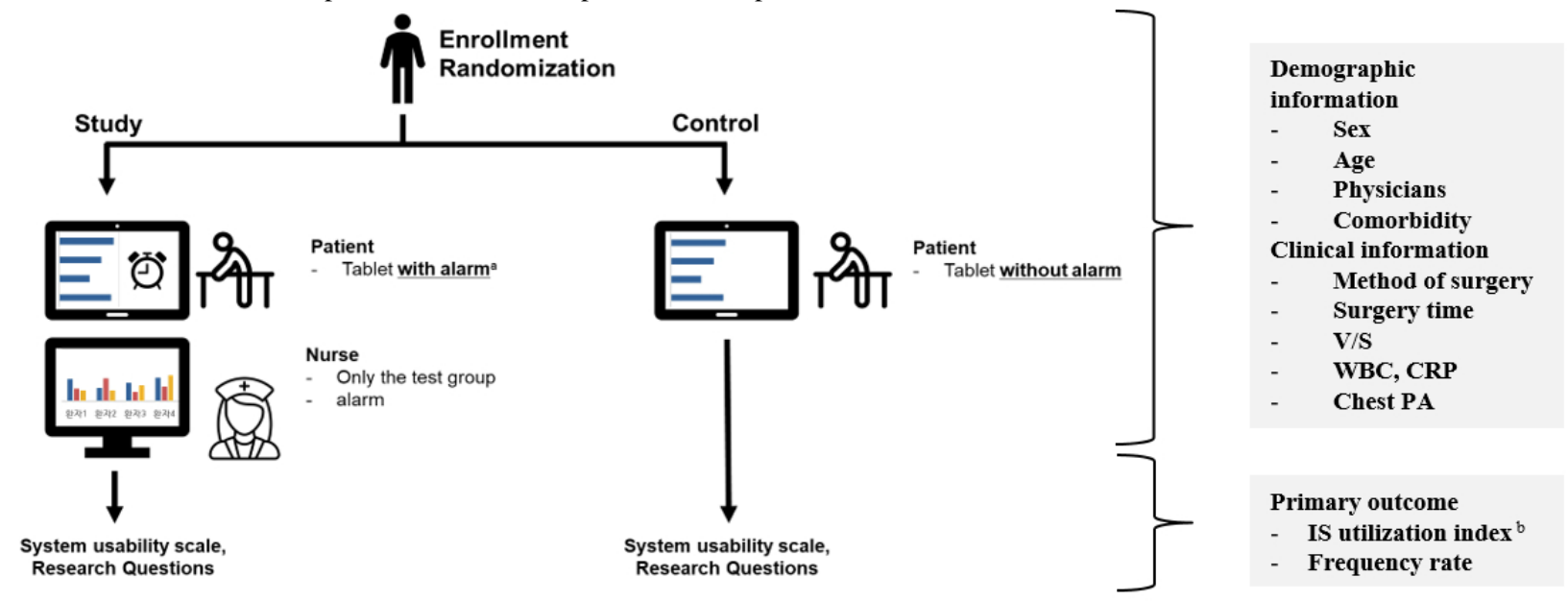

Process flow

Collecting information

Figure 2. Screenshot of the Go-breath app (left) and dashboard (right). The original version was in Korean, but it was modified to display English.
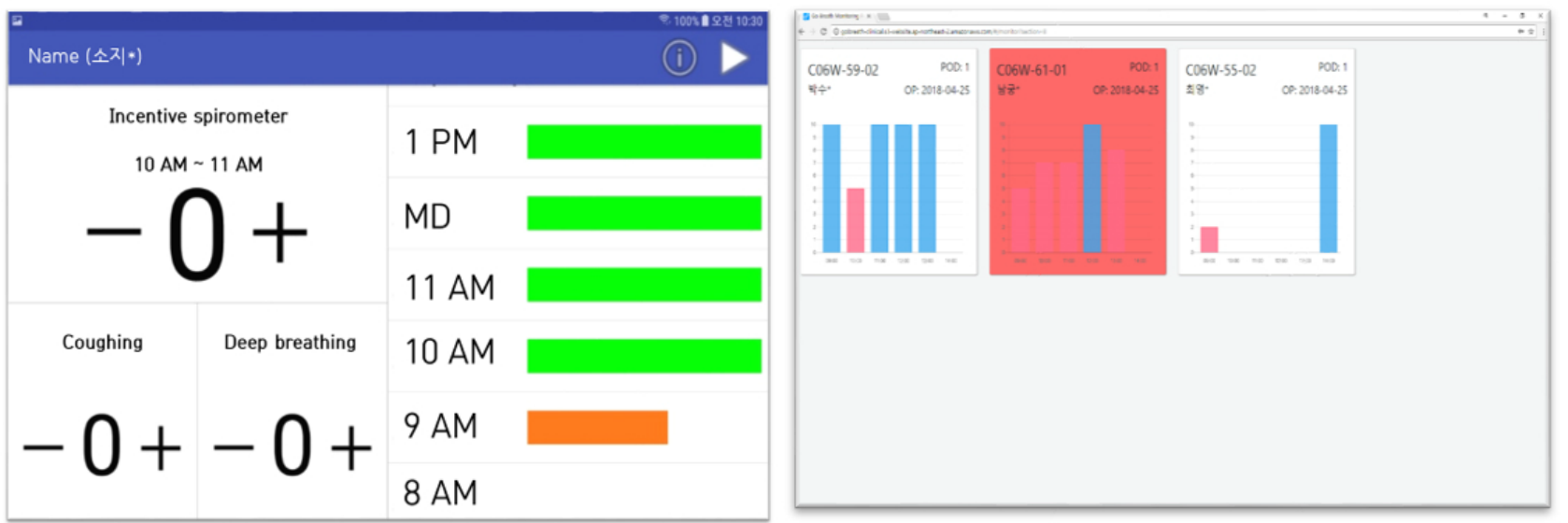


\section{Go-breath App}

The main function of the Go-breath app was to allow for self-reporting and frequency monitoring of IS, deep breathing, and active coughing in real-time. In principle, patients were instructed to use the IS 10 times every hour and simultaneously report it to the app. The optimal number of times to use the IS was derived from the literature [2,6]. Patients could also check on their current state and edit previous indices they had input (Figure 3).

The Go-breath app was set to alarm when the number of IS uses did not reach 10 in an hour. The app was set to ring $10 \mathrm{~min}$ before the end of each hour to give the patients time to complete the expected number of hourly uses. When the patients fulfilled their hourly IS use, the alarm would silence automatically. However, patients could silence the alarm. When the mute icon was pressed, the alarm would be deactivated for 2 hours and would reactivate by default. This functionality was provided because some of the patients could be away from their bed for various reasons, and the alarm could disturb other patients. The system remained frozen during the study period. We had preserved the anonymity of the patients by an unidentified number.

\section{Go-breath Dashboard}

Only information from the test group was displayed on the Go-breath dashboard. The dashboard showed IS performance that did not include other measures, such as deep breathing and active coughing. Each patient was displayed as a card with his or her location and POD information. For each card, the patient's ISI during the most recent 6 hours was displayed as a bar graph. If the most recent hourly ISI was not optimal (below 10), the card turned red. The timing and alarm rules were identical to that of the Go-breath app (Figure 3).

\section{Major Outcomes}

\section{Primary Outcome}

We developed the ISI, which ranged from 0 to 120 per day. The maximum score was 240 for a 2-day observation period. We developed an outcome index using clinical experts and supporting literature [2,6-8]. The ISI was defined as 10 points per each hour, the frequency of IS use was 10 times or more for that hour. If the frequency was below 10 for that hour, the score was rated as 0. ISI was only measured from 9:00 am to 9:00 $\mathrm{pm}$ at PODs 1 and 2. We compared the ISI of the test group and control group.

\section{Secondary Outcome}

The secondary outcome was the System Usability Scale (SUS). At the end of the study, patients completed an offline questionnaire to evaluate the system using the SUS, which is widely used in health information technology research [15-20]. The questionnaire measures the usability of hardware and software products, and it comprises only 10 items that respondents score on a 5-point Likert scale. Answers were converted to a final 0 - to 100-point score, and the higher the score, the more usable the product $[17,19,21]$.

Figure 3. System architecture. API: application programming interface; AWS: Amazon Web Service.

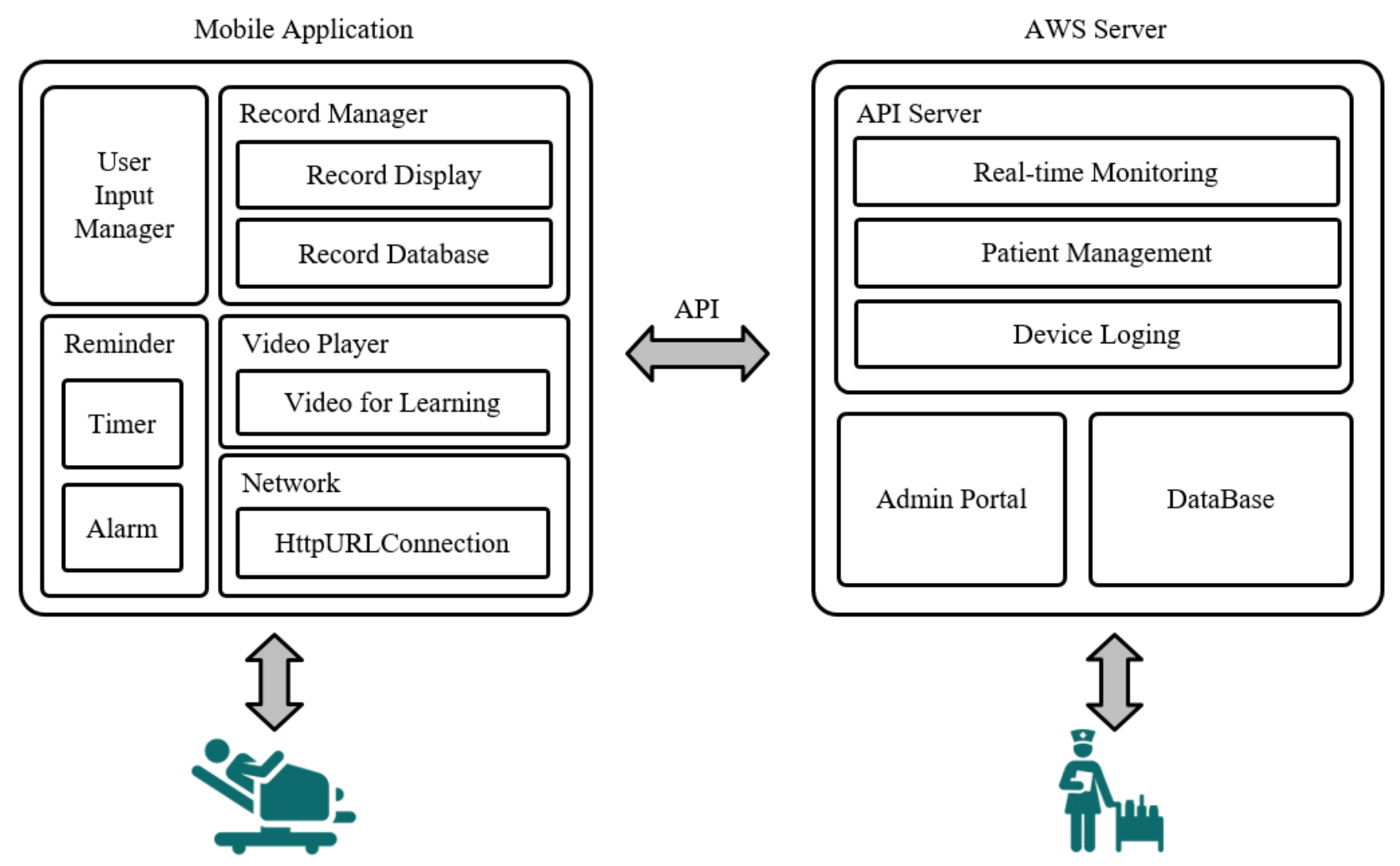




\section{Other Outcomes}

In addition to the major outcomes, we measured IS use frequency, active coughing frequency, deep breathing, and clinical results (as length of stay). Clinical data, such as surgery, laboratory data including white blood cell, C-reactive protein, vital signs (fever), and chest posterior to anterior, and length of stay were also collected.

\section{Interviews}

After the study, a brief face-to-face interview with every patient was performed by a research assistant. Patients answered whether the system was helpful or not and rated the score. Patients' subjective opinions of the system were also gathered during the process.

\section{Data Collection}

We collected the patients' baseline demographic information along with variables associated with surgery including surgeon, type of surgery, and duration of the operation. In the trial, all participants were asked to record log when they started and finished Go-breath app every day. Missing entries were interpreted as a missed value.

\section{Sample Size Calculation}

We calculated the sample size of this study with the G-power 3.1 program (Statistical power analyses using $\mathrm{G}^{*}$ Power 3.1 [22]). Several assumptions were made to set the sample population. The power was set to 0.90 , significance level was set to .05 , and effect size was 1.00 . The minimum number of samples for the Wilcoxon rank-sum test was 19 in each group. We assumed that the ISI would be different by $60 \%$ (12/20; test group) versus $40 \%$ (8/20; control group), with SDs for each group. This assumption was made based on expert opinions because there was no evidence that described IS frequency. Under these conditions, the sample size was 19 patients, and finally, 22 patients were selected for each group considering a dropout rate of $10 \%$.

\section{Results}

\section{Study Participants}

We recruited 44 patients from April to May 2018, with 22 patients allocated to the test group and 22 patients allocated to the control group from patients who used the Go-breath app at a single tertiary hospital in South Korea. A total of 2 patients were excluded because of clinical conditions. The overall average age was 55.9 (SD 12.9) years. The proportion of female patients was $34.1 \%$. All patients had gastric cancer, and the overall average surgery time was 169 (SD 46.2) $\mathrm{min}$. The demographic information of both groups is shown in Table 1.

\section{Major Outcomes}

The primary ISI outcome and the secondary SUS outcome are shown in Table 2, and no statistically significant differences were noted in these outcomes between the test and control groups. SUS of both groups showed good to excellent grade [21].

For the performance measures, both the IS rate count and deep breathing showed a higher performance without a statistical significance. However, active coughing showed a significantly higher performance in the test group compared with the control group. For the clinical results, including inflammatory markers and pulmonary complications, there were no statistically significant differences between the test and control groups (Table 3).

\section{Interviews}

For the usefulness questionnaire, $90.0 \%$ of the test group and $90.9 \%$ of the control group answered yes. There were 3 domains of opinions: function addition, function alteration, and etc. The 2 most wanted functions were exercise tracking and peer patients' information, and the most frequent complaint was about Wi-Fi connection issues (Table 4). 
Table 1. Demographic characteristics of patients in the test and control groups.

\begin{tabular}{|c|c|c|}
\hline Category & Test group $(\mathrm{N}=22)$ & Control group $(\mathrm{N}=22)$ \\
\hline \multicolumn{3}{|l|}{ Sex, n (\%) } \\
\hline Female & $6(27)$ & $9(40)$ \\
\hline Male & $16(72)$ & $13(59)$ \\
\hline Dropout, n (\%) & $2(9)$ & $0(0)$ \\
\hline \multicolumn{3}{|l|}{ Age (years), n (\%) } \\
\hline $30-40$ & $1(4)$ & $4(18)$ \\
\hline $50-60$ & $12(54)$ & $11(50)$ \\
\hline $70-80$ & $8(36)$ & $7(31)$ \\
\hline Over 80 & $1(4)$ & $0(0)$ \\
\hline \multicolumn{3}{|l|}{ Method of surgery, n (\%) } \\
\hline Laparotomy & $10(45)$ & $8(36)$ \\
\hline Laparoscopy, robotics & $12(54)$ & $14(63)$ \\
\hline \multicolumn{3}{|l|}{ Physicians, n (\%) } \\
\hline Dr K & $9(40)$ & $7(31)$ \\
\hline Dr B & $3(13)$ & $3(13)$ \\
\hline Dr S & $5(22)$ & $5(22)$ \\
\hline Dr L & $5(22)$ & $7(31)$ \\
\hline \multicolumn{3}{|l|}{ Comorbidity, n (\%) } \\
\hline Tuberculosis & $0(0)$ & $1(4)$ \\
\hline Diabetes mellitus & $2(8)$ & $2(9)$ \\
\hline Hypertension & $4(20)$ & $8(36)$ \\
\hline Others & $2(10)$ & $2(9)$ \\
\hline Time of surgery ${ }^{\mathrm{a}}(\min )$, mean $(\mathrm{SD})$ & $168(54)$ & $170(36)$ \\
\hline
\end{tabular}

${ }^{\mathrm{a}}$ Time of surgery was defined as the time from anesthesia to extubation time.

Table 2. Major outcomes.

\begin{tabular}{lllc}
\hline Index & Test group (N=20), mean (SD) & Control group (N=22), mean (SD) & $P$ value \\
\hline ISI $^{\mathrm{a}}$ & $113.5(0.8)$ & $93.2(71.2)$ & .22 \\
SUS $^{\mathrm{b}}$ & $79.25(20.59)$ & $79.43(18.83)$ & .94 \\
\hline
\end{tabular}

${ }^{\mathrm{a}}$ ISI (incentive spirometer utilization index) is a score of 10 points per hour if over 10 times from 9 am to 9 pm for 2 days, with a total maximum score of 240 .

${ }^{\mathrm{b}}$ SUS: System Usability Scale. 
Table 3. Other outcomes.

\begin{tabular}{|c|c|c|c|}
\hline Category & Test group $(\mathrm{N}=20)$ & Control group $(\mathrm{N}=22)$ & $P$ value \\
\hline \multicolumn{4}{|l|}{ Performance rate, mean (SD) } \\
\hline Incentive spirometer, count & $139.5(61.2)$ & $119.0(84.5)$ & .27 \\
\hline Active coughing & $79.0(52.78)$ & $44.1(43.62)$ & .04 \\
\hline Deep breathing & $107.8(66.8)$ & $94.8(88.33)$ & .49 \\
\hline \multicolumn{4}{|l|}{ Laboratory results, mean (SD) } \\
\hline $\mathrm{WBC}^{\mathrm{a}}, \mathrm{k} / \mathrm{mL}$ & $6.2(2.8)$ & $5.9(1.8)$ & .93 \\
\hline $\mathrm{CRP}^{\mathrm{b}}, \mathrm{mg} / \mathrm{dL}$ & $8.1(4.0)$ & $8.2(2.9)$ & .07 \\
\hline Length of stay, mean (SD) & $10.8(1.6)$ & $10.40(1.00)$ & .57 \\
\hline \multicolumn{4}{|l|}{ Chest PA ${ }^{c}, n(\%)$} \\
\hline Atelectasis & $2(10)$ & $3(15)$ & .64 \\
\hline Fever $^{\mathrm{d}}, \mathrm{n}(\%)$ & $6(30)$ & $10(45)$ & .79 \\
\hline
\end{tabular}

${ }^{\mathrm{a}}$ WBC: white blood cell.

${ }^{\mathrm{b}} \mathrm{CRP}$ : C-reactive protein.

${ }^{\mathrm{c}} \mathrm{PA}$ : posterior to anterior.

${ }^{d}$ Fever was defined as $37.5^{\circ} \mathrm{C}\left(99.5^{\circ} \mathrm{F}\right)$, and it means the number of people who have been checked for fever at least once.

Table 4. Components of the qualitative interview.

\begin{tabular}{|c|c|c|}
\hline Part & Contents & Responses (n) \\
\hline \multirow[t]{7}{*}{ Function addition $(\mathrm{N}=12)$} & "I would like to have the ability to check the number of steps when walking after surgery." & 3 \\
\hline & $\begin{array}{l}\text { "I would like a report function on the results of my performance compared with other patients } \\
\text { and checking the number of balls up." }\end{array}$ & 3 \\
\hline & "I wish I could hang it on a portable pole and small size device." & 2 \\
\hline & $\begin{array}{l}\text { "I would like to be provided with the training methods for coughing and deep breathing in addi- } \\
\text { tion." }\end{array}$ & 1 \\
\hline & "I wish that the software has more fun-factors." & 1 \\
\hline & "I wish my IS use data gets entered automatically." & 1 \\
\hline & "I would like to have a medication schedule on the device." & 1 \\
\hline \multirow[t]{3}{*}{ Alert function } & "I wish there was a notice function when the goal is achieved." & 2 \\
\hline & "I would like to be able to customize the alarm settings myself." & 1 \\
\hline & "I was very worried that the alarm would be annoying to other patients." & 1 \\
\hline \multirow[t]{3}{*}{ Other components } & "I did not want to use it because of Wi-Fi connection issues." & 3 \\
\hline & "The device and solution were somewhat difficult for the elderly." & 3 \\
\hline & $\begin{array}{l}\text { "I expected the nurses to inform me when my performance was not good, only to be disappointed } \\
\text { when they did not." }\end{array}$ & 2 \\
\hline
\end{tabular}

\section{Discussion}

\section{Principal Findings}

The purpose of this study was to assess the effectiveness of a mobile phone app on improving the performance of the IS by postoperative patients. The major intervention of this study was to provide an interactive feedback system for patients to improve their breathing exercise behaviors. To our knowledge, this is the first RCT that involves the IS and a mobile phone app even though multiple research studies had previously shown their feasibility $[9,23]$. We enrolled 42 patients, split between a test and control group, and compared their ISI, which showed an approximate $20 \%$ difference between the 2 groups (113.5, SD 50.8 vs 93.2, SD 71.2), although the difference was not statistically significant.

\section{Strength and Limitations}

The negative outcome could have been influenced by several factors. First, the SDs were very high in both groups. This means the study population was heterogeneous with respect to IS use, which was not considered when designing the clinical trial. To the authors' knowledge, there was no literature with specific 
measures of the IS. The SD was higher than other in-hospital indices, which was hard to foresee before the trial. In general, the evidence on the effectiveness of this app is limited and needs further investigation before implementation in mobile health care. Recent studies have shown a substantial variation in the effectiveness of mobile health apps. Previous studies have not reported a significant difference in clinical outcomes in mobile health research because of the difficulties in RCT settings, such as small sample sizes and low levels of research design. However, an effective clinical assessment of mobile health is hard to achieve, and there have been various attempts to determine health engagement and behavioral factors [24,25].

The second possible reason was that the feedback mechanism could have influenced the control group more than intended. Patients behave differently because of several factors, and many patients come from a nonmedical background. However, studies involving the behaviors of hospitalized patients still need more exploration. For example, the Diabetes Prevention Program was introduced to Mobile App America by insurance companies. Mobile App America is a company with proven effective mobile phone app development, and it focuses on participant engagement and app value [26-29]. Individuals involved in technological development, engineering, and theory tend to focus on the technology itself [30]. However, health care user engagement in a postoperation setting includes unpredictable factors such as caregiving, word setting, Wi-Fi connections, and nurse feedback.

The third possible reason could be the effectiveness of the alarms. Many patients were sharing rooms with other patients and were very concerned about the sound of the alarm bothering others. To make this kind of trial more successful, patient feedback should be carefully considered.

Nevertheless, the effect of the mobile phone app was demonstrated along with the details of the ISI and performance rate. All results were based on the difference between the test and control groups. Although the effectiveness of the app was not proven, the possible utility of a mobile phone app in the postoperation setting was shown. In addition, this was the first trial to collect real-time evidence of IS device use over a long duration. Although we could not find a standard for how patients should perform the IS, this research is significant by itself.

The negative outcome of this study is because of the diversity of the patients' behavior than the effectiveness of the intervention. Both the test and control groups showed a wide $\mathrm{SD}$, which diminished the statistical power. This could have been prevented by appropriate sample size calculations, but to the authors' knowledge, no other study had revealed such a wide difference in hospitalized patients' behavior with postoperative conditions.

The reason we had negative outcomes in the SUS could vary. Though we wanted to make an interactive system and evaluate its utility, a majority of the device's functions were very similar in both groups. From the users' aspect, reporting on the system could have been the main task. The alarm function was a major intervention for recognition, but it could be a minor task for patients.

This study did not detect a statistically significant difference with Go-breath app usage between the test group and the control group. However, considerable differences were still observed between the 2 groups, and such differences may demonstrate the possible effects of ICT on patient IS engagement. The surgical procedures, comorbidities (Multimedia Appendix 2), and length of anesthesia could have also influenced the outcome, which must have been minimized by randomization.

This study had some limitations. First, we could not measure the frequency of the use of the Go-breath dashboard because of the difficulty of implementing it without substantially disturbing the clinical routines of the acting nurses. Second, because our system relied on the input from a number of patients (nonblinded), the results could have been biased by the patients' subjective cognition, willingness, or adherence to digital devices. The existence of family members could have also influenced the input. However, even with these potential biases, inputting the data itself could have positively influenced the use of IS, as with other mobile solutions [22]. The third limitation is related to the second one; the control group could have been substantially influenced by the device when inputting IS use. Even without its alarm function, individuals in the test group could see their current IS usage status, which could have encouraged them to use it more frequently, aggravating the Hawthorne effect. Finally, there was no confirmed function for the performance rate. Although we made it possible to modify the number of previous performances, it did not guarantee the accuracy of the number of IS uses. To improve this, a sensor that automatically measures the number of IS uses could provide more accurate data.

\section{Conclusions}

The use of the Go-breath app resulted in considerable differences between the test group and control group but with no statistically significant differences.

\section{Acknowledgments}

This research was supported by the Basic Science Research Program through the National Research Foundation of Korea (NRF), funded by the Ministry of Education (NRF-2017R1D1A1B03029526), and processed as one of the creative lab projects by Samsung electronics.

\section{Conflicts of Interest}

IP, GS, NH, and $\mathrm{CH}$ are employees of the company that developed the Go-breath app.

Editorial notice: This randomized study was only retrospectively registered. The editor granted an exception of ICMJE rules for prospective registration of randomized trials because the risk of bias appears low and the study was considered formative. However, 
readers are advised to carefully assess the validity of any potential explicit or implicit claims related to primary outcomes or effectiveness, as retrospective registration does not prevent authors from changing their outcome measures retrospectively.

\title{
Multimedia Appendix 1
}

Video clips for incentive spirometer after surgery.

[DOCX File, 2MB-Multimedia Appendix 1]

\section{Multimedia Appendix 2}

Co-morbidities in patients undergoing open surgery and robotic or laparoscopic procedures.

[DOCX File, 14KB-Multimedia Appendix 2]

\author{
Multimedia Appendix 3 \\ CONSORT - EHEALTH checklist (V 1.6.1). \\ [PDF File (Adobe PDF File), 3MB-Multimedia Appendix 3]
}

\section{References}

1. García-Miguel FJ, Serrano-Aguilar PG, López-Bastida J. Preoperative assessment. Lancet 2003 Nov 22;362(9397):1749-1757. [doi: 10.1016/S0140-6736(03)14857-X] [Medline: 14643127]

2. Restrepo RD, Wettstein R, Wittnebel L, Tracy M. Incentive spirometry: 2011. Respir Care 2011 Oct;56(10):1600-1604 [FREE Full text] [doi: 10.4187/respcare.01471] [Medline: 22008401]

3. Sebio R, Yáñez-Brage MI, Giménez-Moolhuyzen E, Valenza MC, Reychler G, Cahalin LP. Impact of a pre-operative pulmonary rehabilitation program on functional performance in patients undergoing video-assisted thoracic surgery for lung cancer. Arch Bronconeumol 2016 May;52(5):231-232 [FREE Full text] [doi: 10.1016/j.arbres.2015.10.013] [Medline: 26747731]

4. Kumar AS, Alaparthi GK, Augustine AJ, Pazhyaottayil ZC, Ramakrishna A, Krishnakumar SK. Comparison of flow and volume incentive spirometry on pulmonary function and exercise tolerance in open abdominal surgery: a randomized clinical trial. J Clin Diagn Res 2016 Jan 1;10(1):KC01-KC06 [FREE Full text] [doi: 10.7860/JCDR/2016/16164.7064] [Medline: 26894090]

5. Malik PR, Fahim C, Vernon J, Thomas P, Schieman C, Finley CJ, et al. Incentive spirometry after lung resection: a randomized controlled trial. Ann Thorac Surg 2018 Aug;106(2):340-345. [doi: 10.1016/j.athoracsur.2018.03.051] [Medline: 29702071]

6. Hall JC, Tarala RA, Tapper J, Hall JL. Prevention of respiratory complications after abdominal surgery: a randomised clinical trial. Br Med J 1996 Jan 20;312(7024):148-152. [doi: 10.1136/bmj.312.7024.148] [Medline: $\underline{\text { 8563533] }}$

7. Westwood K, Griffin M, Roberts K, Williams M, Yoong K, Digger T. Incentive spirometry decreases respiratory complications following major abdominal surgery. Surgeon 2007 Dec;5(6):339-342. [doi: 10.1016/S1479-666X(07)80086-2] [Medline: $\underline{18080608]}$

8. Agostini P, Singh S. Incentive spirometry following thoracic surgery: what should we be doing? Physiotherapy 2009 Jun;95(2):76-82. [doi: 10.1016/j.physio.2008.11.003] [Medline: 19627688]

9. Jaensson M, Dahlberg K, Eriksson M, Nilsson U. Evaluation of postoperative recovery in day surgery patients using a mobile phone application: a multicentre randomized trial. Br J Anaesth 2017 Nov 1;119(5):1030-1038 [FREE Full text] [doi: 10.1093/bja/aex331] [Medline: 29077818]

10. Hung WW, Ross JS, Farber J, Siu AL. Evaluation of the Mobile Acute Care of the Elderly (MACE) service. JAMA Intern Med 2013 Jun 10;173(11):990-996 [FREE Full text] [doi: 10.1001/jamainternmed.2013.478] [Medline: 23608775]

11. Semple J, Sharpe S, Murnaghan M, Theodoropoulos J, Metcalfe K. Using a mobile app for monitoring post-operative quality of recovery of patients at home: a feasibility study. JMIR Mhealth Uhealth 2015 Feb 12;3(1):e18 [FREE Full text] [doi: 10.2196/mhealth.3929] [Medline: 25679749]

12. Williams A, Bhatti U, Alam H, Nikolian V. The role of telemedicine in postoperative care. Mhealth 2018;4:11 [FREE Full text] [doi: 10.21037/mhealth.2018.04.03] [Medline: 29963556]

13. Dadlani R, Mani S, Mohan D, Rajgopalan N, Thakar S, Aryan S, et al. The impact of telemedicine in the postoperative care of the neurosurgery patient in an outpatient clinic: a unique perspective of this valuable resource in the developing world--an experience of more than 3000 teleconsultations. World Neurosurg 2014;82(3-4):270-283. [doi: 10.1016/j.wneu.2014.05.027] [Medline: 24887533]

14. Siddle J, Pang P, Weaver C, Weinstein E, O'Donnell D, Arkins T, et al. Mobile integrated health to reduce post-discharge acute care visits: a pilot study. Am J Emerg Med 2018 May;36(5):843-845. [doi: 10.1016/j.ajem.2017.12.064] [Medline: $\underline{29317154]}$ 
15. Borsci S, Federici S, Lauriola M. On the dimensionality of the System Usability Scale: a test of alternative measurement models. Cogn Process 2009 Aug;10(3):193-197. [doi: 10.1007/s10339-009-0268-9] [Medline: 19565283]

16. Borsci S, Federici S, Bacci S, Gnaldi M, Bartolucci F. Assessing user satisfaction in the era of user experience: comparison of the SUS, UMUX, and UMUX-LITE as a function of product experience. Int J Hum Comput Stud 2015 Jun 24;31(8):484-495. [doi: 10.1080/10447318.2015.1064648]

17. Kortum P, Bangor A. Usability ratings for everyday products measured with the System Usability Scale. Int J Hum Comput Stud 2012 Apr 11;29(2):67-76. [doi: 10.1080/10447318.2012.681221]

18. Sauro J, Lewis JR. Quantifying the User Experience: Practical Statistics for User Research. USA: Morgan Kaufmann; 2012.

19. Brooke J. SUS-a quick and dirty usability scale. In: Usability Evaluation in Industry. UK: CRC Press; 1996:4-7.

20. Bangor A, Kortum P, Miller J. Journ Usability Stud. 2009 May. Determining what individual SUS scores mean: adding an adjective rating scale URL: http://uxpajournal.org/

determining-what-individual-sus-scores-mean-adding-an-adjective-rating-scale/

21. Lehmann M, Monte K, Barach P, Kindler CH. Postoperative patient complaints: a prospective interview study of 12,276 patients. J Clin Anesth 2010 Feb;22(1):13-21. [doi: 10.1016/j.jclinane.2009.02.015] [Medline: 20206846]

22. Faul F, Erdfelder E, Buchner A, Lang AG. Statistical power analyses using G*Power 3.1: tests for correlation and regression analyses. Behav Res Methods 2009 Nov;41(4):1149-1160. [doi: 10.3758/BRM.41.4.1149] [Medline: 19897823]

23. Overdijkink SB, Velu AV, Rosman AN, van Beukering MD, Kok M, Steegers-Theunissen RP. The usability and effectiveness of mobile health technology-based lifestyle and medical intervention apps supporting health care during pregnancy: systematic review. JMIR Mhealth Uhealth 2018 Apr 24;6(4):e109 [FREE Full text] [doi: 10.2196/mhealth.8834] [Medline: 29691216]

24. Robinson MD, Branham AR, Locklear A, Robertson S, Gridley T. Measuring satisfaction and usability of FaceTime for virtual visits in patients with uncontrolled diabetes. Telemed J E Health 2015 Aug 21. [doi: 10.1089/tmj.2014.0238] [Medline: 26295592]

25. Ackermann RT, Finch EA, Brizendine E, Zhou H, Marrero DG. Translating the diabetes prevention program into the community. The DEPLOY pilot study. Am J Prev Med 2008 Oct;35(4):357-363 [FREE Full text] [doi: 10.1016/j.amepre.2008.06.035] [Medline: $\underline{18779029}$ ]

26. Diabetes Prevention Program Research Group. The Diabetes Prevention Program (DPP): description of lifestyle intervention. Diabetes Care 2002 Dec 1;25(12):2165-2171 [FREE Full text] [doi: 10.2337/diacare.25.12.2165] [Medline: 12453955]

27. Yu X, Chau JP, Huo L. The effectiveness of traditional Chinese medicine-based lifestyle interventions on biomedical, psychosocial, and behavioral outcomes in individuals with type 2 diabetes: a systematic review with meta-analysis. Int $\mathbf{J}$ Nurs Stud 2018 Apr;80:165-180. [doi: 10.1016/j.ijnurstu.2018.01.009] [Medline: 29471267]

28. Xiao L, Yank V, Wilson SR, Lavori PW, Ma J. Two-year weight-loss maintenance in primary care-based Diabetes Prevention Program lifestyle interventions. Nutr Diabetes 2013 Jun;3:e76 [FREE Full text] [doi: 10.1038/nutd.2013.17] [Medline: 23797383]

29. Richards KA, Jones E. Customer relationship management: finding value drivers. Indust Mark Manag 2008 Apr;37(2):120-130. [doi: 10.1016/j.indmarman.2006.08.005]

30. Soh JY, Cha WC, Chang DK, Hwang JH, Kim K, Rha M, et al. Development and validation of a multidisciplinary mobile care system for patients with advanced gastrointestinal cancer: interventional observation study. JMIR Mhealth Uhealth 2018 May 7;6(5):e115 [FREE Full text] [doi: 10.2196/mhealth.9363] [Medline: 29735478]

\author{
Abbreviations \\ ICT: information and communication technology \\ ICU: intensive care unit \\ IS: incentive spirometer \\ ISI: incentive spirometer index \\ NRF: National Research Foundation of Korea \\ POD: postoperative day \\ RCT: randomized controlled trial \\ SUS: System Usability Scale
}


Edited by $G$ Eysenbach; submitted 13.09.18; peer-reviewed by Y Carter, S Borsci; comments to author 08.10.18; revised version received 26.11.18; accepted 31.12.18; published 19.02.19

Please cite as:

Soh JY, Lee SU, Lee I, Yoon KS, Song C, Kim NH, Sohn TS, Bae JM, Chang DK, Cha WC

A Mobile Phone-Based Self-Monitoring Tool for Perioperative Gastric Cancer Patients With Incentive Spirometer: Randomized Controlled Trial

JMIR Mhealth Uhealth 2019;7(2):e12204

URL: http://mhealth.jmir.org/2019/2/e12204/

doi: $10.2196 / 12204$

PMID: $\underline{30777844}$

(CJi Yeong Soh, Se Uk Lee, Inpyo Lee, Ki Sang Yoon, Changho Song, Nam Hun Kim, Tae Sung Sohn, Jae Moon Bae, Dong Kyung Chang, Won Chul Cha. Originally published in JMIR Mhealth and Uhealth (http://mhealth.jmir.org), 19.02.2019. This is an open-access article distributed under the terms of the Creative Commons Attribution License (https://creativecommons.org/licenses/by/4.0/), which permits unrestricted use, distribution, and reproduction in any medium, provided the original work, first published in JMIR mhealth and uhealth, is properly cited. The complete bibliographic information, a link to the original publication on http://mhealth.jmir.org/, as well as this copyright and license information must be included. 